\title{
Application of statistical methods in human airway flow analysis
}

\author{
F. Lizal ${ }^{1}$, M. Fusek ${ }^{2}$, J. Jedelsky ${ }^{1} \&$ M. Jicha ${ }^{1}$ \\ ${ }^{I}$ Energy Institute, Faculty of Mechanical Engineering, \\ Brno University of Technology, Czech Republic \\ ${ }^{2}$ Institute of Mathematics, Faculty of Mechanical Engineering, \\ Brno University of Technology, Czech Republic
}

\begin{abstract}
Understanding of the air flow in human airways is the cornerstone for targeted delivery of a medication to the lungs. Direct in-vivo measurement in lungs is complicated; therefore in-vitro measurements in human lung models are frequently performed employing optical measurement methods. Irregularly sampled data acquired by Phase Doppler Anemometry in various locations of a model of human lungs for different breathing conditions were statistically processed to facilitate comparison and influence of diverse factors on the lung airflow. Tests based on signs of differences, Kendall's rank correlation coefficient test and Spearman's rank correlation coefficient test were used to detect a linear trend between the samples, while a median test of randomness and a turning point test were used to detect differences of a periodical nature. The presented statistical tools allow detection of inter-cycle variability in velocity course as well as evaluation of the influence of breathing pattern change or gradual flow development in an airway. Application of the above mentioned methods on our data confirmed the essential influence of lung geometry on flow profiles and revealed remarkable flow behaviour in the main bronchi. Usability of the statistical tools is not limited to measurements in human lung models, but can be extended to any flow measurements, for comparison of irregularly and regularly sampled data and also for comparison of numerical simulations with experiments.

Keywords: flow analysis, human airways, lung flow, statistical analysis, airflow measurement.
\end{abstract}




\section{Introduction}

Targeted delivery of aerosolized medication to human lungs is of growing interest, since respiratory as well as systemic diseases can be treated using inhaled pharmaceuticals. Inhalation route represents a less harmful and a less painful way of drug administration when compared with the intravenous and oral methods, respectively. The necessary precondition to achieve minimal sideeffects of medication is to deliver the right amount of drug to the right location. Failing to achieve this goal leads to increased load of organism which may result into wastage of often very expensive medication (Kleinstreuer et al. [1]).

Deposition area of inhaled aerosol depends on many factors, such as breathing pattern, lung capacity, geometry of airways, size and shape of particles, their initial velocity and others. Measurement of influence of these parameters on aerosol deposition in vivo is complicated due to restricted access and variability of geometry related to physiological factors; therefore in vitro experiments are frequently performed on models of human airways with various degree of simplification [2-4]. Also numerical modelling has been often used to simulate the flow and fate of inhaled particles [5-7].

In vitro measurement of flow velocity in different parts of airways can be performed using optical measuring methods, such as Particle Image Velocimetry (PIV) or Phase Doppler Anemometry (PDA). Application of PIV is limited by optical distortions on the model/fluid boundaries arising from different refractive index of air and material of the model. This problem could be avoided by using liquid with identical refractive index as the material of model walls as a carrier medium for tracing particles [8, 9]. However, for measurements with aerosol PDA is the only possibility. In addition to particle velocity PDA measures the size of particles and consequently can serve for investigation of clustering of particles or velocity spectra analysis, for it provides time-resolved velocity record. The disadvantage of the PDA is only point-wise measurement, hence other methods have to be used for identification of the general flow behaviour and identification of eddies and wakes.

Comparison of PDA results acquired for different input conditions such as various breathing patterns or various sizes of particles is often a complex issue, but can be solved by assessment of experienced researcher; nevertheless, the result is always influenced by a subjective perspective. Statistical methods presented in this paper allow unbiased evaluation of such data sets.

\section{Methods}

Realistic human airway model was used for PDA measurements of velocity and size of aerosol particles in 16 cross-sections. Breathing was simulated using computer controlled mechanism moving piston in a cylinder with sinusoidal shape of the piston velocity. Measured velocities were then processed to allow comparison of various breathing regimes and velocities in different measuring location employing statistical tests of randomness. 


\subsection{Measurement setup}

The airway model was fabricated from optically transparent thin walled silicone as described in Lizal et al. [10]. The model incorporates airways down from pharynx up to fourth bifurcation level, and has asymmetrical branching and realistic curved tubes, fig. 1. In this paper only seven cross-sections (marked A $\mathrm{G}$ in fig. 1) were included and 5 points in each cross-section were used for comparison. Nomenclature of measuring points is as follows: the first character represents cross-section, the second stands for measuring point ( $\mathrm{F}$ - front, $\mathrm{B}-$ back, $\mathrm{R}$ - right, L - left, no letter - point in the axis), please note that due to different orientation of the tube axis in left and right bronchi and trachea, position $\mathrm{R}$ is in the left bronchus on the lower side of the tube, while in the right bronchus position $\mathrm{R}$ is on the upper side of the tube. The third entry of the code is the distance of the point from the tube axis.

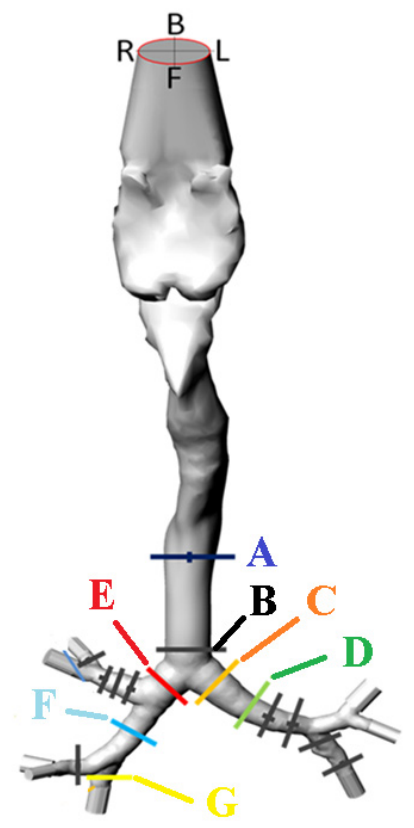

Figure 1: $\quad$ Model of human airways with measuring cross-sections.

The measuring setup (fig. 2) consists of Condensation Monodisperse Aerosol Generator (4) (CMAG, TSI 3475, TSI Inc.) producing liquid $3 \mu \mathrm{m}$ particles from di-2-ethyl-hexyl sebacate (DEHS); Process Aerosol Monitor (PAM, TSI 3375, TSI Inc.) for on-line measurement of size and concentration of aerosol particles, mixing chamber (3), where aerosol is mixed with air from breathing mechanism (5) driven by motor (6) and controlled by computer to simulate three breathing patterns (resting conditions with tidal volume $V_{t}=0.5$ liter and period $T=4 \mathrm{~s}$, 
deep breathing with $V_{t}=1$ liter and $T=4 \mathrm{~s}$ and light activity with $V_{t}=1.5$ liter and $T=3 \mathrm{~s}$ ); realistic model of human lungs (1) and PDA transmitting and receiving optics (7). Aerosol is led to an elastic bag (2) which collects particles for the inhalation phase.

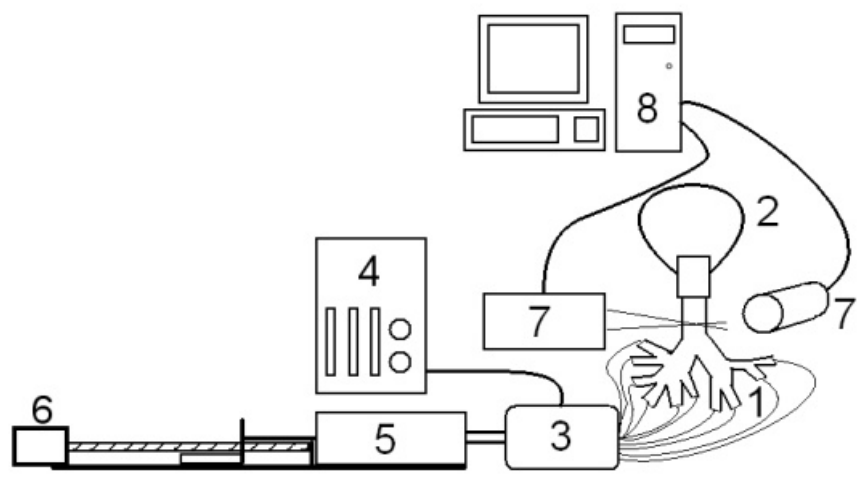

Figure 2: Diagram of the measurement setup.

PDA system (Dantec Dynamics, Skovlunde, Denmark) was adjusted for timeresolved measurement of axial velocity component and for complementary measurement of the particle size (for details see Jedelsky et al. [11]).

\subsection{Data processing}

The irregularly sampled data acquired by Phase Doppler Anemometry describe the breathing cycle in various locations of a model for different breathing patterns. Therefore, the data files contain various numbers of non-equidistantly distributed measurements. Novel software CIRDA [12] was created for processing of this kind of data. The software is suitable for comparison of large irregularly sampled data files.

To reduce the size of data files and to overcome the difficulty of irregularly sampled data, smoothing techniques were used, that is the kernel regression with local linear kernel estimator

$$
f_{h}(x)=\frac{1}{n} \sum_{i=1}^{n} \frac{\left[s_{2}(x)-\left(x_{i}-x\right) s_{1}(x)\right] K_{h}\left(x_{i}-x\right) y_{i}}{s_{2}(x) s_{0}(x)-\left[s_{1}(x)\right]^{2}} .
$$

where

$$
s_{r}(x)=\frac{1}{n} \sum_{i=1}^{n}\left(x_{i}-x\right)^{r} K_{h}\left(x_{i}-x\right)
$$

and Gaussian kernel 


$$
K_{h}(u)=\frac{1}{h \sqrt{2 \pi}} e^{-\frac{u^{2}}{2 h^{2}}}
$$

In our case, when a rather regular structure of data is observed, the use of some simple rule for the optimal bandwidth selection is sufficient. Thus the bandwidth is of the form (see Bowman and Azzalini [13])

$$
h_{x}=\left(\frac{4}{3 n}\right)^{\frac{1}{5}} \frac{\operatorname{median}\left(\left|x_{i}-\tilde{x}\right|\right)}{0.6745}
$$

where $\tilde{x}$ represents the sample median. In order to cover the variability of the data in the direction of both $\mathrm{x}$ - and $\mathrm{y}$-axis, the bandwidth is selected as

$$
h=\sqrt{h_{x} h_{y}}
$$

The local linear estimator was chosen because of its favourable asymptotic properties and boundary behaviour (see e.g. Wand and Jones [14]).

A pair of irregularly sampled data files was processed by the above mentioned regression techniques, which results in regression curves with regularly sampled values. These regression curves were subtracted from each other and normalized by the square root of the sum of variances of the particular data files. This technique gave rise to a set of velocity values scattered around a constant. For cases where different breathing patterns were observed (e.g., normal breathing vs. light activity), particular regression curves were scaled to one of the breathing modes.

To decide whether two velocity profiles are similar or whether they differ, it is necessary to find out whether the subtracted velocity values are randomly scattered around a constant or whether there is a systematic component. Tests of randomness, as described below, were used to elucidate the velocity profiles

\subsection{Tests of randomness}

Tests of randomness (Cipra [15]) are often used for identification of a random, or systematic component (linear or periodic) in the series. The hypotheses simply are $H_{0}: x_{i} \sim$ i.i.d. (independent and identically distributed) and $H_{1}$ : otherwise.

\subsubsection{Test based on signs of differences}

The test based on signs of first differences in the series $x_{1}, \ldots, x_{n}$ can be carried out by counting the plus and minus signs in the differences. The test is based on the number $k$ of positive differences $x_{i+1}-x_{i}, i=1, \ldots, n-1$, in the series.

Let's define a random variable $V_{i}$ as

$$
V_{i}=1 \text { for } x_{i+1}>x_{i}
$$




$$
V_{i}=0 \text { for } x_{i+1}<x_{i}
$$

It can be shown, that the number of positive differences $k$ has the expected value

$$
E(k)=\frac{n-1}{2}
$$

and variance

$$
\operatorname{Var}(k)=\frac{n+1}{12}
$$

Variable $k$ has the asymptotic normal distribution, thus for a sufficiently large sample size $n$ the hypothesis $H_{0}$ is rejected on significance level $\alpha$ if

$$
\frac{|k-(n-1) / 2|}{\sqrt{(n+1) / 12}} \geq u(\alpha / 2) .
$$

where $u(\alpha / 2)$ is a quantile of standard normal distribution $\mathrm{N}(0,1)$.

\subsubsection{Kendall's rank correlation coefficient test}

Let $v$ be the number of pairs $x_{i}$ and $x_{j}$, that $x_{i}<x_{j}$ for $i<j$. Kendall's rank correlation coefficient

$$
\tau=\frac{4 v}{n(n-1)}-1 .
$$

has the asymptotic normal distribution with zero mean and variance

$$
\operatorname{Var}(\tau)=\frac{2(2 n+5)}{9 n(n-1)}
$$

The hypothesis $H_{0}$ is rejected on the significance level $\alpha$ if

$$
\frac{|\tau|}{\sqrt{\frac{2(2 n+5)}{9 n(n-1)}}} \geq u(\alpha / 2) .
$$

\subsubsection{Spearman's rank correlation coefficient test}

Let $q_{1}, \ldots, q_{n}$ be the ranked observations in the series $x_{1}, \ldots, x_{n}$. Ordinal ranking is used, thus all items receive distinct ordinal numbers, including items that compare equal. For example, if $x_{1}=10, x_{2}=1, x_{3}=5, x_{4}=1$, then $q_{1}=4, q_{2}=1$, $q_{3}=3, q_{4}=2$. Spearman's rank correlation coefficient $\rho$ 


$$
\rho=1-\frac{6}{n\left(n^{2}-1\right)} \sum_{i=1}^{n}\left(i-q_{i}\right)^{2} .
$$

has the asymptotic normal distribution and the hypothesis $H_{0}$ is rejected on the significance level $\alpha$ if

$$
|\rho| \sqrt{n-1} \geq u(\alpha / 2)
$$

\subsubsection{Turning point test}

This test is based on the number of turning points (peaks and troughs) in the series $x_{1}, \ldots, x_{n}$. The upper turning point $x_{i}$ is the local maximum $x_{i-1}<x_{i}>x_{i+1}$ and the lower turning point $x_{i}$ is the local minimum $x_{i-1}>x_{i}<x_{i+1}, i=2, \ldots, n-1$. Let $p$ be the number of upper and lower turning points in the series. It can be shown that

$$
\begin{gathered}
E(p)=\frac{2(n-2)}{3}, \\
\operatorname{Var}(p)=\frac{16 n-29}{90} .
\end{gathered}
$$

Variable $p$ has the asymptotic normal distribution and the hypothesis $H_{0}$ is rejected on the significance level $\alpha$ if

$$
\frac{|p-2(n-2) / 3|}{\sqrt{(16 n-29) / 90}} \geq u(\alpha / 2) .
$$

\subsubsection{Median test of randomness}

This test is based on the sample median $\tilde{x}$ of the series $x_{1}, \ldots, x_{n}$. Each observation is compared with the median of the series and assigned "+" to those samples larger than the median and "-_" to the samples less than the median. Assume that the ordered series has $n$ samples, $n_{1}$ of "+”, $n_{2}$ of "-_", $n_{3}$ of observations equal to median and $n=n_{1}+n_{2}+n_{3}$. If $n_{1} \neq n_{2}$, then one observation equal to median is assigned to "+" or "-" in order to fulfill $n_{1}=n_{2}$. The numbers of runs of to "+" and "-_" are denoted $r_{1}, r_{2}$ and then total number of runs is $r=r_{1}+r_{2}$.

The hypothesis $H_{0}$ is rejected on the significance level $\alpha$ if

$$
\frac{\left|r-\left(n_{1}+1\right)\right|}{\sqrt{n_{1}\left(n_{1}-1\right) /\left(2 n_{1}-1\right)}} \geq u(\alpha / 2) .
$$

The test based on signs of differences, Kendall's rank correlation coefficient test and Spearman's rank correlation coefficient test are recommended (Cipra [15]) 
for linear trend detection in a given series. On the contrary, if there is a possibility of presence of periodic component in the data, the turning point test and median test of randomness are recommended.

\section{Results and discussion}

The first step of the data analysis using statistical tests implemented in software CIRDA involved tuning in of the kernel size for the regression of data. In general, the larger the kernel size, the stronger the suppression of the small fluctuations and vice versa. There is no rule for determination of the kernel size, because the size always depends on the character of the flow and phenomena, which is to be studied. Therefore in our case seven sizes of kernel were tested in the range 0.1 to 10 times the basic kernel size on three test cases. The first case were 2 cycles from one measurement, where no significant difference was expected; the second case was comparison of flow in tracheal cross-sections A and B, where major differences were expected; and the third case was comparison of cross-sections $\mathrm{E}$ and $\mathrm{G}$, where completely different flow characteristics are present. The best agreement of the software results with expected values was achieved using kernel with 0.5 size of the basic kernel size. This size was used for comparison of all data files.

The sample results are presented in fig. 3. In the upper part are presented compared data sets. Both graphs include eight overlapped cycles plotted on a
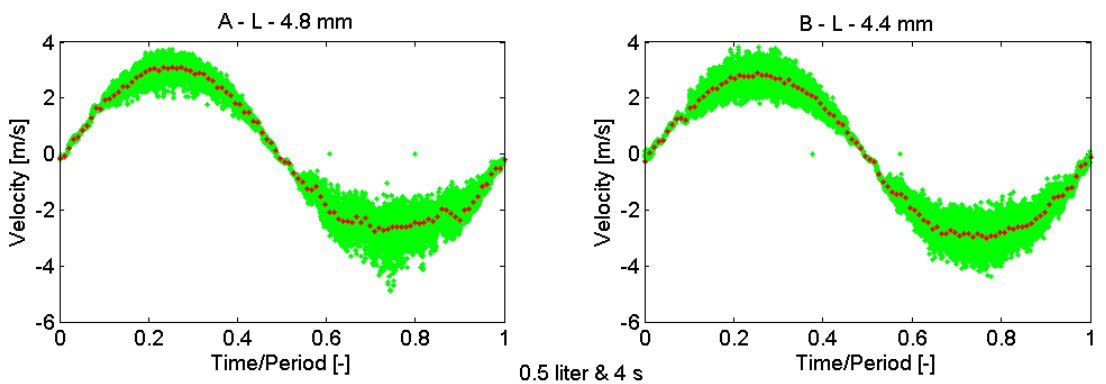

0.5 liter \& $4 \mathrm{~s}$

tests: 00001

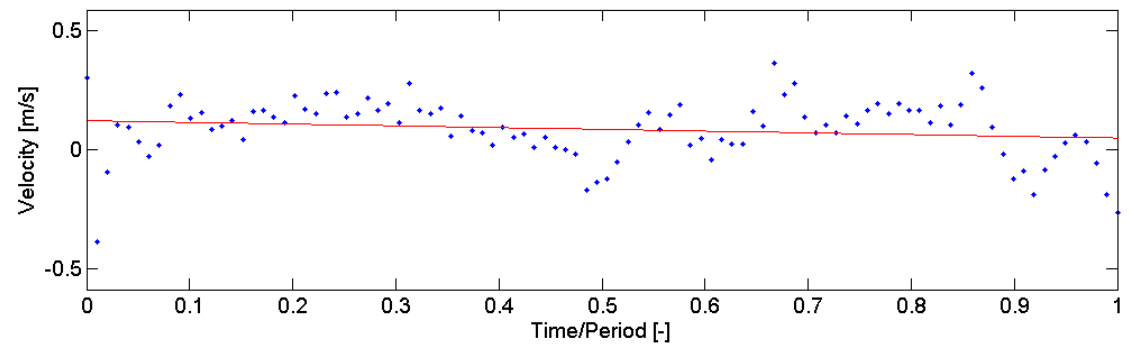

Figure 3: Comparison of measurement in points $\mathrm{L}$ above the left principal bronchus in trachea cross-section A (on the top left) and B (on the top right); subtracted velocities with linear regression (bottom). 
dimensionless horizontal axis and regression of the cycle. Original sinusoidal course of the velocity induced by breathing mechanism is influenced by passage of the air through larynx and following airways during inhalation and by mixing of air from daughter branches during exhalation. Passage of a vortex through the measuring volume appears in the PDA velocity record as a wavelet (successive drop and increase or reverse) in the velocity course. The bottom part of fig. 3 contains calculated difference of velocities.

Table 1: $\quad$ Comparison of breathing patterns.

\begin{tabular}{|c|c|c|c|c|}
\hline & & $\begin{array}{c}0.5 \text { liter \& } 4 \mathrm{~s} \text { vs. } \\
1 \text { liter \& } 4 \mathrm{~s}\end{array}$ & $\begin{array}{l}1 \text { liter \& } 4 \mathrm{~s} \text { vs. } \\
1.5 \text { liter \& } 3 \mathrm{~s}\end{array}$ & $\begin{array}{c}0.5 \text { liter \& } 4 \mathrm{~s} \text { vs. } \\
1.5 \text { liter } \& 3 \mathrm{~s}\end{array}$ \\
\hline \multirow{4}{*}{$A$} & $0 \mathrm{~mm}$ & $\begin{array}{llllll}0 & 1 & 1 & 0 & 1\end{array}$ & $\begin{array}{llllll}0 & 1 & 1 & & 0 & 1 \\
\end{array}$ & $\begin{array}{lllllll} & 0 & 1 & 1 & & 1 & 1\end{array}$ \\
\hline & $\mathrm{R} 4.4 \mathrm{~mm}$ & $\begin{array}{llllll}0 & 1 & 1 & & 0 & 1 \\
\end{array}$ & $\begin{array}{llllll}0 & 1 & 1 & & 0 & 1 \\
\end{array}$ & $\begin{array}{llllll}0 & 0 & 0 & & 1 & 1 \\
\end{array}$ \\
\hline & $\mathrm{L} 4.4 \mathrm{~mm}$ & $\begin{array}{llllll}0 & 1 & 1 & & 0 & 1 \\
\end{array}$ & $\begin{array}{llllll}0 & 1 & 1 & & 0 & 1 \\
\end{array}$ & $\begin{array}{llllll}0 & 1 & 1 & & 0 & 1 \\
\end{array}$ \\
\hline & $\mathrm{F} 4.4 \mathrm{~mm}$ & $\begin{array}{llllll}0 & 1 & 1 & & 1 & 1 \\
\end{array}$ & $\begin{array}{llllll}0 & 1 & 1 & & 0 & 1 \\
\end{array}$ & $\begin{array}{llllll}0 & 1 & 1 & & 1 & 1 \\
\end{array}$ \\
\hline & B $4.4 \mathrm{~mm}$ & $\begin{array}{llllll}1 & 1 & 1 & & 0 & 1\end{array}$ & $\begin{array}{llllll}1 & 1 & 1 & & 0 & 1\end{array}$ & $\begin{array}{llllll}0 & 1 & 1 & & 1 & 1\end{array}$ \\
\hline \multirow{5}{*}{ B } & $0 \mathrm{~mm}$ & $\begin{array}{llllll}0 & 0 & 0 & & 0 & 1\end{array}$ & $\begin{array}{llllll}0 & 1 & 1 & & 0 & 1\end{array}$ & $\begin{array}{llllll}0 & 1 & 1 & & 0 & 1\end{array}$ \\
\hline & $\mathrm{R} 4.8 \mathrm{~mm}$ & $\begin{array}{llllll}0 & 1 & 1 & & 0 & 1 \\
\end{array}$ & $\begin{array}{llllll}0 & 1 & 1 & & 0 & 1 \\
\end{array}$ & $\begin{array}{llllll}1 & 0 & 0 & & 1 & 1 \\
\end{array}$ \\
\hline & $\mathrm{L} 4.8 \mathrm{~mm}$ & $\begin{array}{llllll}0 & 0 & 0 & & 0 & 1 \\
\end{array}$ & $\begin{array}{llllll}0 & 1 & 1 & & 0 & 1 \\
\end{array}$ & $\begin{array}{llllll}0 & 1 & 1 & & 1 & 1 \\
\end{array}$ \\
\hline & $\mathrm{F} 4.8 \mathrm{~mm}$ & $\begin{array}{llllll}0 & 1 & 1 & & 0 & 1 \\
\end{array}$ & $\begin{array}{llllll}0 & 1 & 1 & & 0 & 1 \\
\end{array}$ & $\begin{array}{llllll}0 & 1 & 1 & & 0 & 1 \\
\end{array}$ \\
\hline & B $4.8 \mathrm{~mm}$ & $\begin{array}{llllll}0 & 1 & 1 & & 0 & 1\end{array}$ & $\begin{array}{llllll}1 & 0 & 0 & 1 & 1\end{array}$ & $\begin{array}{llllll}0 & 1 & 1 & & 1 & 1 \\
\end{array}$ \\
\hline \multirow{5}{*}{$\mathrm{C}$} & $0 \mathrm{~mm}$ & $\begin{array}{llllll}0 & 0 & 0 & & 1 & 1 \\
\end{array}$ & $\begin{array}{llllll}0 & 0 & 0 & 0 & 1 \\
\end{array}$ & $\begin{array}{llllll}0 & 0 & 0 & & 1 & 1 \\
\end{array}$ \\
\hline & $\mathrm{R} 3 \mathrm{~mm}$ & $\begin{array}{llllll}0 & 0 & 0 & & 0 & 1\end{array}$ & $\begin{array}{llllll}0 & 0 & 0 & & 0 & 1\end{array}$ & NED \\
\hline & L $3 \mathrm{~mm}$ & $\begin{array}{llllll}0 & 0 & 0 & & 0 & 1 \\
\end{array}$ & $\begin{array}{llllll}0 & 0 & 0 & & 0 & 1 \\
\end{array}$ & $\begin{array}{llllll} & 1 & 1 & & 0 & 1 \\
\end{array}$ \\
\hline & F $3 \mathrm{~mm}$ & $\begin{array}{llllll}0 & 0 & 0 & & 1 & 1 \\
\end{array}$ & $\begin{array}{llllll}0 & 1 & 1 & & 1 & 1 \\
\end{array}$ & $\begin{array}{lllllll}0 & 0 & 0 & & 0 & 1 \\
\end{array}$ \\
\hline & B $3 \mathrm{~mm}$ & $\begin{array}{llllll}0 & 1 & 1 & & 0 & 1 \\
\end{array}$ & $\begin{array}{llllll}1 & 0 & 0 & & 0 & 1 \\
\end{array}$ & $\begin{array}{llllll}1 & 1 & 1 & & 1 & 1 \\
\end{array}$ \\
\hline \multirow{5}{*}{$\mathrm{D}$} & $0 \mathrm{~mm}$ & $\begin{array}{llllll}0 & 1 & 1 & & 0 & 1 \\
\end{array}$ & $\begin{array}{llllll}0 & 1 & 1 & & 0 & 1 \\
\end{array}$ & $\begin{array}{llllll}0 & 0 & 0 & & 0 & 1 \\
\end{array}$ \\
\hline & $\mathrm{L} 2.3 \mathrm{~mm}$ & $\begin{array}{llllll}0 & 0 & 1 & & 1 & 1 \\
\end{array}$ & $\begin{array}{llllll}1 & 0 & 0 & 0 & 1 \\
\end{array}$ & $\begin{array}{llllll}0 & 1 & 1 & & 1 & 1 \\
\end{array}$ \\
\hline & $\mathrm{R} 2.3 \mathrm{~mm}$ & $\begin{array}{llllll}0 & 0 & 0 & & 0 & 1 \\
\end{array}$ & $\begin{array}{llllll}0 & 1 & 1 & & 0 & 1 \\
\end{array}$ & $\begin{array}{llllll}0 & 0 & 0 & & 0 & 1\end{array}$ \\
\hline & $\mathrm{F} 2.3 \mathrm{~mm}$ & $\begin{array}{lllllll}0 & 1 & 1 & & 1 & 1 \\
\end{array}$ & $\begin{array}{llllll}0 & 1 & 1 & & 1 & 1 \\
\end{array}$ & $\begin{array}{llllll}0 & 1 & 1 & & 0 & 1 \\
\end{array}$ \\
\hline & B $2.3 \mathrm{~mm}$ & $\begin{array}{lllllll}0 & 1 & 1 & & 0 & 1 \\
\end{array}$ & $\begin{array}{lllllll}0 & 1 & 1 & & 1 & 1 \\
\end{array}$ & $\begin{array}{lllllll}0 & 1 & 1 & & 1 & 1 \\
\end{array}$ \\
\hline \multirow{5}{*}{$\mathrm{E}$} & $0 \mathrm{~mm}$ & $\begin{array}{llllll}1 & 1 & 1 & & 0 & 1 \\
\end{array}$ & $\begin{array}{llllll}0 & 1 & 1 & & 0 & 1 \\
\end{array}$ & $\begin{array}{llllll}0 & 1 & 1 & & 1 & 1 \\
\end{array}$ \\
\hline & R $3.5 \mathrm{~mm}$ & $\begin{array}{llllll}0 & 0 & 0 & 0 & 1\end{array}$ & $\begin{array}{llllll}0 & 1 & 1 & & 1 & 1 \\
\end{array}$ & $\begin{array}{llllll}0 & 0 & 0 & & 1 & 1 \\
\end{array}$ \\
\hline & L $3.5 \mathrm{~mm}$ & $\begin{array}{llllll}0 & 0 & 0 & & 0 & 1 \\
\end{array}$ & NED & NED \\
\hline & F $3.5 \mathrm{~mm}$ & $\begin{array}{llllll}0 & 0 & 0 & & 1 & 1 \\
\end{array}$ & $\begin{array}{llllll}0 & 1 & 1 & & 1 & 1 \\
\end{array}$ & 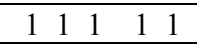 \\
\hline & B $3.5 \mathrm{~mm}$ & $\begin{array}{lllllll} & 0 & 1 & 1 & & 1 & 0 \\
\end{array}$ & NED & 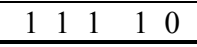 \\
\hline \multirow{5}{*}{$\mathrm{F}$} & $0 \mathrm{~mm}$ & $\begin{array}{llllll}0 & 0 & 0 & & 1 & 1 \\
\end{array}$ & $\begin{array}{llllll}0 & 1 & 1 & & 1 & 1 \\
\end{array}$ & $\begin{array}{llllll}0 & 1 & 1 & & 1 & 1 \\
\end{array}$ \\
\hline & $\mathrm{R} 2 \mathrm{~mm}$ & NED & $\begin{array}{llllll}0 & 1 & 1 & & 0 & 1 \\
\end{array}$ & $\begin{array}{llllll}0 & 1 & 1 & & 0 & 1 \\
\end{array}$ \\
\hline & $\mathrm{L} 2 \mathrm{~mm}$ & $\begin{array}{llllll}0 & 0 & 0 & & 0 & 1 \\
\end{array}$ & $\begin{array}{llllll}0 & 1 & 1 & & 0 & 1 \\
\end{array}$ & $\begin{array}{llllll}0 & 1 & 1 & & 0 & 1 \\
\end{array}$ \\
\hline & F $2 \mathrm{~mm}$ & $\begin{array}{lllllll} & 0 & 1 & 1 & & 1 & 1 \\
\end{array}$ & $\begin{array}{llllll}0 & 1 & 1 & & 1 & 1 \\
\end{array}$ & $\begin{array}{llllll}0 & 1 & 1 & & 0 & 1 \\
\end{array}$ \\
\hline & B $2 \mathrm{~mm}$ & 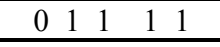 & $\begin{array}{llllll}0 & 1 & 1 & & 1 & 1 \\
\end{array}$ & $\begin{array}{llllll}0 & 1 & 1 & & 1 & 1 \\
\end{array}$ \\
\hline $\mathrm{G}$ & $0 \mathrm{~mm}$ & $\begin{array}{llllll}0 & 1 & 1 & & 1 & 1\end{array}$ & $\begin{array}{llllll}0 & 1 & 1 & & 1 & 1\end{array}$ & $\begin{array}{llllll}0 & 1 & 1 & & 1 & 1\end{array}$ \\
\hline
\end{tabular}

NED (not enough data) - due to complicated conditions in some measuring points was not possible to acquire sufficient number of data points for relevant statistical analysis 
The result of statistical analysis consists of five digits, which correspond to the outcome of the signs of differences, Kendall's, Spearman's, turning point and median test respectively. The first three digits answer the supposition about the existence of a linear trend and the last two represent the result of search for existence of periodical trend in the data. Number 0 stands for failure to reject the null hypothesis, that the two data sets are independent and identically distributed on the significance level $\alpha=0.05$; number 1 stands for rejection of the null hypothesis.

All data files were primarily tested for inter-cycle variability. Every data record contains five to eight subsequent cycles; second and last but one cycle were used for testing. All data records except those with not enough data (NED) gave the same result - failure to reject the null hypothesis from all tests. Interpretation is that the flow behaviour is repeated every cycle with sufficient accuracy. Therefore all cycles from one data record were condensed into one dimensionless cycle (overlapped) and the following comparisons were performed on the dimensionless cycle.

Comparison of the influence of three breathing patterns mentioned in section 2.1 is presented in table 1. It is apparent that the change in flow is more reflected in middle of trachea (cross-section A) than in following airways, where the effect of geometry is essential.

The least influenced cross-section by the breathing pattern change is crosssection $\mathrm{C}$, possibly because of the length of the left principal bronchus which helps to create similar flow patterns especially during the expiration phase. The results also proved that the most sensitive test is the median test, reflecting response to changes of periodical nature; on the contrary the test based on signs of differences, reflecting changes of linear nature, is the least sensitive to breathing pattern change.

Comparison of velocity behavior in corresponding points in different crosssections of the model is presented in table 2. Points for comparison were selected on a basis of supposition where the specific particle flowing out from the one cross-section would enter the second cross-section assuming laminar flow.

The flow in right bronchus is significantly different from the flow in trachea. The test based on signs of differences is insensitive to the different flow, whereas median test gives rejection of the null hypotheses in all cases. Some similarity can be expected in cross-sections of the same branch and surprisingly in crosssections $\mathrm{B}$ and $\mathrm{C}$; however this claim is supported only by turning point test.

\section{Conclusions}

Presented statistical tools allow unbiased comparison of different data sets. Application of the tests on velocity data measured by PDA in realistic model of human airways proved essential influence of the lung geometry on the flow. Our results showed that the velocity profile in the left lung preserves basic shape for resting conditions breathing regime. For the more rapid breathing, the flow 
Table 2: Comparison of flow in different locations. Column headers denote compared cross-sections, row labels denote measuring points: $\mathrm{O}$ tube axis, $\mathrm{R}$ - right, $\mathrm{L}$ - left, $\mathrm{F}$ - front, $\mathrm{B}$ - back (see fig. 1).

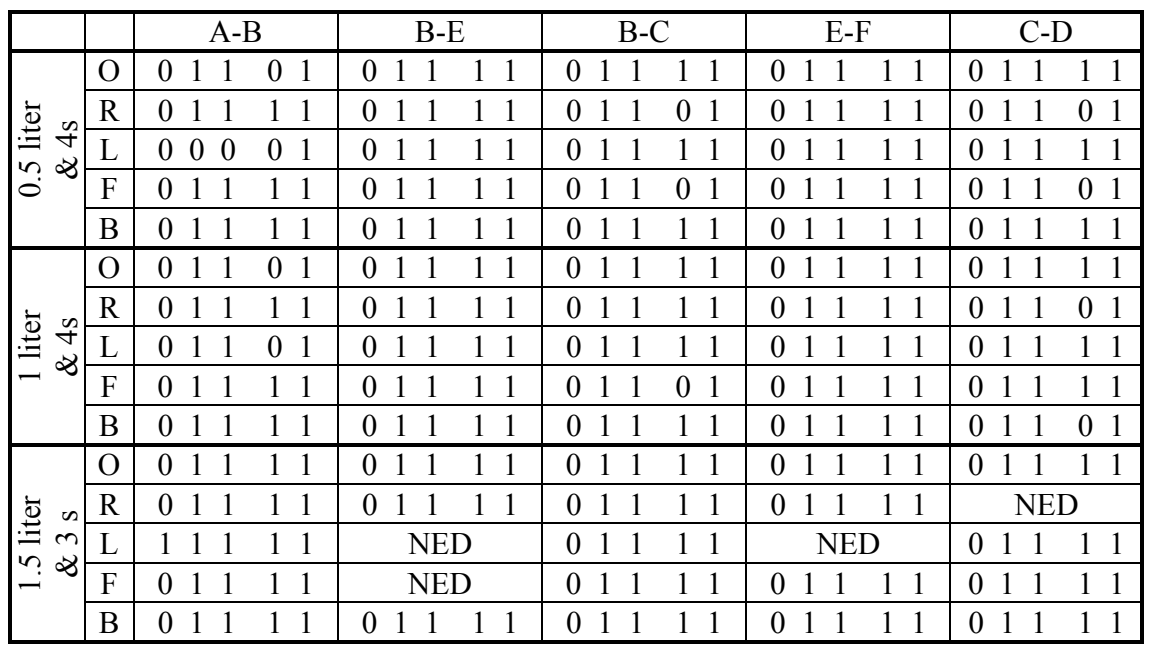

NED (not enough data) - due to complicated conditions in some measuring points was not possible to acquire sufficient number of data points for relevant statistical analysis

changes quickly during the passage through the airways, and statistical tests found significant differences in almost all measuring points. The statistical tests are also useful for detection of inter-cycle variability in velocity course. It should be noted that the most difficult part of the process is the interpretation of the results. In the first step of the statistical analysis the kernel size should be adjusted. Different choices of the size give different results due to suppression or amplification of small fluctuations. However, each setting provides specific information which can be useful for specific purpose. Usability of the statistical tools is not limited for measurements in human lungs models, but can be extended to any flow measurements, for comparison of irregularly and regularly sampled data and also for comparison of numerical simulations with experiments.

\section{Acknowledgements}

The authors are grateful to Mark Omara (Center for Air Resources Engineering and Science at Clarkson University) for reviewing this manuscript. This work was supported by the Czech Grant Agency under the grant GA P105/11/1339, by COST Action 0806 project OC10052 and by project ME 09030 of the program KONTAKT supported by the Czech Ministry of Education, Youth and Sports. 


\section{References}

[1] Kleinstreuer, C., Zhang, Z., Li, Z., Roberts, W. L. and Rojas, C., A new methodology for targeting drug-aerosols in the human respiratory system. International Journal of Heat and Mass Transfer. 51(23-24), pp. 5578$5589,2008$.

[2] Gurman, J. L., Lippmann, M. and Schlesinger, R. B., Particle deposition in replicate casts of the human upper tracheobronchial tree under constant and cyclic inspiratory flow. 1. Experimental. Aerosol Science and Technology. 3(3), pp. 245-252, 1984.

[3] Kim, C. S. and Fisher, D. M., Deposition characteristics of aerosol particles in sequentially bifurcating airway models. Aerosol Science and Technology. 31(2-3), pp. 198-220, 1999.

[4] Zhou, Y. and Cheng, Y. S., Particle deposition in a cast of human tracheobronchial airways. Aerosol Science and Technology. 39(6), pp. 492$500,2005$.

[5] Katz, I. M., Davis, B. M. and Martonen, T. B. A numerical study of particle motion within the human larynx and trachea. Journal of Aerosol Science. 30(2), pp. 173-183, 1999.

[6] Isaacs, K. K., Schlesinger, R. B. and Martonen, T. B., Three-dimensional computational fluid dynamics simulations of particle deposition in the tracheobronchial tree. Journal of Aerosol Medicine-Deposition Clearance and Effects in the Lung. 19(3), pp. 344-352, 2006.

[7] Lin, C. L., Tawhai, M. H., McLennan, G. and Hoffman, E. A., Characteristics of the turbulent laryngeal jet and its effect on airflow in the human intra-thoracic airways. Respiratory Physiology \& Neurobiology. 157(2-3), pp. 295-309, 2007.

[8] Adler, K. and Brucker, C., Dynamic flow in a realistic model of the upper human lung airways. Experiments in Fluids. 43(2-3) , pp. 411-423, 2007.

[9] Hopkins, L. M., Kelly, J. T., Wexler, A. S. and Prasad, A. K., Particle image velocimetry measurements in complex geometries. Experiments in Fluids. 29(1), pp. 91-95, 2000.

[10] Lizal, F., Elcner, J., Hopke, P. K., Jedelsky, J. and Jicha, M., Development of a realistic human airway model. Proceedings of the Institution of Mechanical Engineers Part H-Journal of Engineering in Medicine. 226(H3), pp. 197-207, 2012.

[11] Jedelsky, J., Lizal, F. and Jicha, M., Some aspects of particle motion under cyclic flow in realistic human airway model. Proceedings of the 21st ISTP, Kaohsiung, Taiwan, 2010.

[12] Fusek, M., CIRDA 1.0 (software for Comparison of IRregularly sampled DAta), Brno University of Technology, Brno, 2011, www.sw.howto.cz/ CIRDA/

[13] Bowman, A. W. and Azzalini, A., Applied smoothing techniques for data analysis : the kernel approach with S-Plus illustrations, Clarendon Press; Oxford University Press, Oxford, New York, 1997. 
[14] Wand, M. P. and Jones, M. C., Kernel smoothing, 1st ed Chapman and Hall, London; New York, 1995.

[15] Cipra, T., Analýza časových řad s aplikacemi v ekonomii, SNTL, Praha, 1986. 